\title{
Reflexões iniciais sobre a terminologia designativa de área e subáreas do Português para Falantes de Outras Línguas: um estudo exploratório ${ }^{1}$ \\ Initial reflections on the designative terminology of the area and sub- areas of Portuguese for Speakers of Other Languages: an exploratory study
}

Joel Victor Reis LISBOA*

\begin{abstract}
RESUMO: Este artigo tem como objetivo traçar reflexões iniciais sobre a terminologia designativa da área e de potenciais subáreas de atuação do Português para Falantes de Outras Línguas (PFOL), a partir de dados oriundos de um estudo exploratório realizado. Nossos posicionamentos e reflexões de ordem teórica estão embasados pela Terminologia (CABRÉ, 1999; FREIXA, 2002; KRIEGER; FINATTO, 2004; FERNÁNDEZ-SILVA, 2011, dentre outros), ao passo que a Linguística de Corpus foi utilizada como metodologia para obtenção e análise de dados. Por meio deste estudo exploratório, identificamos uma diversidade de unidades fraseológicas especializadas utilizadas como designadoras da área e de possíveis subáreas do PFOL, bem como verificamos uma alta variação terminológica (formal e conceitual). Os dados e reflexões apresentados neste artigo indicam tópicos a serem investigados ou desenvolvidos em futuras

ABSTRACT: This paper aims to draw initial reflections on the designative terminology of the area and potential subareas of Portuguese for Speakers of Other Languages (PSOL), based on data from an exploratory study. This study was carried out under the theoretical framework of Terminology (CABRÉ, 1999; FREIXA, 2002; KRIEGER; FINATTO, 2004; FERNÁNDEZ-SILVA, 2011, among others), while Corpus Linguistics was the methodology used to collect data and perform the analysis. Through this exploratory study, we identified a range of specialized phraseological units used to designate PSOL area and its potential subareas, as well as a significant terminological variation (both formal and conceptual). The data and reflections presented in this paper indicate topics to be investigated or developed in future research on PSOL designative terminology, such as formal and conceptual terminological standardization, systematization of the domain tree
\end{abstract}

\footnotetext{
${ }^{1}$ O presente trabalho foi realizado com apoio da Coordenação de Aperfeiçoamento de Pessoal de Nível Superior - Brasil (CAPES) - Código de Financiamento 001.

* Mestrando em Estudos Linguísticos pela Universidade Federal de Uberlândia (UFU). ORCID: https://orcid.org/0000-0001-6570-4306. joelvictorlisboa@gmail.com.
} 
pesquisas sobre a terminologia designativa do PFOL, como a realização de uma padronização terminológica formal e conceitual, a sistematização da árvore de domínio da área, a investigação das motivações das variações formais e conceituais, bem como a análise das consequências conceituais da variação formal e as consequências formais da variação conceitual no escopo do PFOL.

PALAVRAS-CHAVE: Português para Falantes de Outras Línguas. Terminologia. Linguística de Corpus. Terminologia designativa. Diversidade e variação terminológica. of this area, investigation on the motivations of formal and conceptual variations, as well as the analysis of the conceptual consequences of formal variation and the formal consequences of conceptual variation in the scope of PSOL.

\section{Introdução}

Português para Falantes de Outras Línguas² (doravante PFOL) é uma área da Linguística Aplicada em ascensão no âmbito mundial, voltada principalmente ao ensino-aprendizagem da língua portuguesa para/por públicos-alvo não lusófonos, e cuja produção científica vem se expandindo vertiginosamente desde o início da década de 1990. Esta área atua em contextos heterogêneos e possui uma diversidade notável de públicos-alvo, cujas necessidades e objetivos linguísticos são consideravelmente distintos. Em virtude disso, cada contexto de atuação do PFOL apresenta especificidades que complexificam a efetividade dos mesmos modelos de ensino nas demais conjunturas em que a área atua.

\footnotetext{
${ }^{2}$ A designação desta área varia na literatura. Em suma, as unidades fraseológicas especializadas utilizadas pelos pesquisadores são as seguintes: Português (como) Língua Estrangeira, Português (como) Língua Não Materna, Português (como) Língua Adicional e Português para Falantes de Outras Línguas. Apesar de não ser a mais consolidada na literatura da área, utilizamos Português para Falantes de Outras Línguas por ser a unidade fraseológica especializada que possui menor grau de variação formal e conceitual segundo as análises em nosso corpus de estudo, como discutido na Seção 5 deste artigo.
} 
A heterogeneidade tangente aos contextos de atuação e aos públicos-alvo atendidos pela área prevê diferenciações de métodos e materiais pedagógicos e, por conseguinte, estimula desdobramentos do PFOL em diferentes subáreas de atuação ${ }^{3}$, bem como fomenta o surgimento de novos conceitos de língua norteadores do ensinoaprendizagem. Esta complexidade referente aos públicos-alvo e aos conceitos de língua norteadores do ensino-aprendizagem é refletida na terminologia ${ }^{4}$ da área. Na literatura do PFOL, nota-se uma alta multiplicidade terminológica designativa tanto da área como de potenciais subáreas de atuação, assim como de diferentes modalidades linguísticas e conceitos de língua.

Com o objetivo de analisar a terminologia designativa da área e das potenciais subáreas do PFOL, realizamos um estudo exploratório com base em um corpus composto por 66 artigos publicados na Revista SIPLE ${ }^{5}$, processados e analisados por meio do programa de análise lexical WordSmith Tools 6.0 (SCOTT, 2012). Este estudo foi realizado segundo a metodologia da Linguística de Corpus (BERBER SARDINHA, 2004; PARODI, 2010; O’KEEFFE; McCARTHY, 2010).

A partir dos dados oriundos deste estudo exploratório, e com base no arcabouço teórico da Terminologia (CABRÉ, 1999; FREIXA, 2002; KRIEGER; FINATTO, 2004; FERNÁNDEZ; SILVA, 2011, dentre outros), traçamos neste artigo algumas reflexões iniciais sobre a terminologia designativa do PFOL, principalmente no que tange à diversidade e à variação terminológica identificadas nas análises do corpus de estudo.

\footnotetext{
${ }^{3}$ Alguns autores referem-se a essas ramificações como "especialidades" ou "áreas". Neste artigo, utilizamos "subáreas" por acreditarmos que esta seja a forma mais adequada para designá-las, haja vista que: (i) elas não se constituem como áreas autônomas em relação ao PFOL; (ii) não as consideramos como especialidades, pois, apesar de ser o ideal, os professores atuantes não necessariamente possuem formação especializada.

${ }^{4}$ Neste artigo, em consonância com Almeida (2000) e Krieger e Finatto (2004), terminologia (com inicial minúscula) refere-se a um conjunto de unidades terminológicas, ao passo que Terminologia (com inicial maiúscula) refere-se à subárea da Linguística que lida com as terminologias e com as comunicações especializadas.

${ }^{5}$ Revista da Sociedade Internacional de Português Língua Estrangeira, disponível em: https://assiple.org/index.php/revista-siple/. Acesso em: 3 dez. 2020.
} 
No âmbito dessas reflexões, apresentamos um esboço da árvore de domínio do PFOL, bem como abordamos a problemática da variação formal e conceitual recorrente na área.

É relevante pontuar que, devido à natureza exploratória da pesquisa, o objetivo não é resolver a problemática terminológica da área, mas apenas trazer reflexões que poderão nortear futuras pesquisas de cunho terminológico voltadas à terminologia analisada neste estudo.

As próximas seções deste artigo encontram-se organizadas da seguinte maneira: primeiramente, introduzimos a complexidade e heterogeneidade tangente aos contextos de atuação da área do PFOL, bem como evidenciamos as motivações do presente estudo. Em seguida, apresentamos os referenciais teóricos da Terminologia que fundamentam esta pesquisa. Logo após, justificamos a eleição da Linguística de Corpus como metodologia para obtenção e análise de dados, e descrevemos brevemente os procedimentos metodológicos realizados, desde a compilação do corpus até os procedimentos de análise. Por fim, apresentamos e discutimos os dados obtidos.

\section{Português para Falantes de Outras Línguas: heterogeneidade, complexidade e ter- minologia}

O interesse de falantes de outras línguas pela língua portuguesa vem crescendo exponencialmente no âmbito mundial. Dentre os fatores que podem fomentar o interesse internacional pelo português estão os seguintes: (i) tratados político-diplomáticos entre países de língua oficial ou majoritária portuguesa e destes países com outros não lusófonos; (ii) presença da língua portuguesa em blocos e agrupamentos econômicos, bem como em centros de tomadas de decisões a nível global; (iii) fortalecimento econômico de alguns países de língua oficial ou majoritária portuguesa; (iv) internacionalização de instituições de ensino e de empresas sediadas em países de língua oficial ou majoritária portuguesa; (v) crescente fluxo migratório em âmbito global, situação 
que fomenta contatos sociolinguísticos entre falantes de diferentes línguas com falantes de língua portuguesa; (vi) crescimento da diáspora da língua portuguesa; (vii) aumento dos contatos entre culturas e do acesso à produção cultural de países de língua portuguesa por meio da internet; (viii) turismo; (ix) número expressivo de falantes de português como língua materna ao redor do mundo; (x) a presença da língua portuguesa em quatro continentes; (xi) a utilização da língua portuguesa como instrumento de diplomacia e expansão de influência geopolíticas dos países lusófonos, dentre muitos outros fatores (AMADO, 2011; 2013; MOITA LOPES, 2013; JATOBÁ, 2015; MALAGUTI, 2015; RETO et al., 2016; BECKHAUSER, 2018).

A partir desse breve panorama de aspectos que possivelmente fomentam o ensino-aprendizagem de PFOL, é possível conjecturar diversos cenários de aprendizagem da língua portuguesa, como, por exemplo: (i) ensino-aprendizagem para/por descendentes de famílias lusófonas vivendo na diáspora, alfabetizados ou não em outras línguas; (ii) ensino-aprendizagem da língua para/por profissionais e estudantes em períodos de intercâmbio em países lusófonos; (iii) ensino-aprendizagem para/por pessoas em situação de migração de crise e para imigrantes voluntários; (iv) ensino-aprendizagem para/por pessoas que vão para países lusófonos como turistas; (v) ensinoaprendizagem para/por pessoas que nasceram em países de língua majoritária ou oficial portuguesa, mas que não possuem o português como língua materna, dentre muitos outros cenários possíveis.

Além disso, essa complexidade se estende aos contextos sociolinguísticos dos aprendizes, como, por exemplo, se estão aprendendo a língua em contextos de (não)imersão, se são falantes de línguas tipologicamente próximas ou distantes, se os aspectos culturais-identitários dos alunos são próximos das culturas da língua-alvo ou não, se o aluno é alfabetizado, está em processo de alfabetização ou se não é alfabetizado etc. 
Esse cenário complexo inerente à área do PFOL estimula ramificações da área em diferentes subáreas de atuação, bem como fomenta a criação/adoção de diferentes conceitos de língua que são basilares para a teorização e para o trabalho didático-pedagógico no escopo do ensino-aprendizagem do PFOL. Isto porque o ensino-aprendizagem não acontece da mesma forma em todos esses cenários, e é preciso considerar as necessidades e objetivos linguísticos dos aprendizes falantes de outras línguas para que o processo de ensino-aprendizagem seja minimamente adequado a cada perfil de público-alvo (BATISTA, 2011).

Na área do PFOL, os pesquisadores designam esses conceitos, bem como a própria área e suas possíveis subáreas, por meio de unidades fraseológicas especializadas (doravante UFEs). Alguns dos exemplos da terminologia designativa da área e de subáreas do PFOL são "Português (como) Língua Estrangeira", "Português (como) Segunda Língua”, "Português (como) Língua Não Materna”, dentre outras UFEs designativas utilizadas pelos pesquisadores/professores da área.

Como essa área está em constante desenvolvimento, o surgimento de novos conceitos, de novas concepções para os conceitos já existentes e de novas UFEs é rotineiro e faz parte dos desenvolvimentos teóricos da área. Na literatura do PFOL é perceptível essa pluralidade terminológica, principalmente no que tange à denominação da própria área (que é bem variante entre publicações de diferentes autores), bem como em relação às potenciais subáreas de atuação.

A motivação do estudo apresentado neste artigo surgiu então pela aspiração em explorar a terminologia designativa de área e subáreas do PFOL, de modo que fosse possível refletir, com base em análises empíricas de uma parcela da produção científica da área, sobre as características desta terminologia. A priori, nossas análises seriam centradas na diversidade terminológica, de modo a mapear as possíveis subáreas do PFOL. Não obstante, nossos dados nos levaram a discutir também a questão da variação terminológica (formal e conceitual), haja vista que a variação é uma característica 
marcante da terminologia sob análise. As reflexões feitas a partir da análise de dados do referido estudo exploratório estão apresentadas na Seção 5.

Na seção a seguir, apresentamos os pressupostos teóricos da Terminologia que fundamentam nossos posicionamentos teóricos e alicerçam nossas análises, bem como tratamos brevemente sobre variação terminológica.

\section{Fundamentação teórica}

Esta pesquisa insere-se no âmbito da Terminologia, subárea da Linguística centrada nas comunicações especializadas, e cujo objeto de estudo central são as unidades terminológicas (CABRÉ, 1999; KRIEGER; FINATTO, 2004). As unidades terminológicas são concebidas como unidades primeiramente linguísticas que, em contextos pragmaticamente marcados, funcionam como signos tridimensionais (dimensões conceitual, linguística e comunicativa) de valor terminológico que, em certa medida, são marcados pela monossemia e pela monorreferencialidade (CABRÉ, 1999; KRIEGER; FINATTO, 2004).

As unidades terminológicas podem ser constituídas por um único item lexical, mas também podem ser agrupamentos lexicais sintagmáticos de valor terminológico que, assim como as unidades terminológicas unilexicais, representam nódulos conceituais no escopo de determinada área técnico-científica (REY, 1995). Esses agrupamentos sintagmáticos de valor terminológico são concebidos como unidades fraseológicas especializadas (UFEs). No caso do PFOL, a terminologia designativa tanto da área como das subáreas de atuação é formada integralmente por UFEs, e, portanto, elas são o objeto central de estudo desta pesquisa.

No âmbito das comunicações especializadas, a utilização de unidades terminológicas é inevitável, haja vista que as terminologias cumprem um papel fundamental na representação, fixação e comunicação de conhecimentos especializados produzidos 
nas áreas técnico-científicas (CABRÉ, 1999). Ademais, “as terminologias auxiliam também a elidir ambigüidades e jogos polissêmicos, freqüentes no uso do chamado léxico geral da língua, contribuindo para uma desejada precisão conceitual" (KRIEGER; FINATTO, 2004, p. 17), afinal, a comunicação especializada naturalmente requer níveis relativamente altos de objetividade e precisão (CABRÉ, 1999).

Não obstante, como evidenciado no início desta seção, as unidades terminológicas e UFEs são, a princípio, unidades linguísticas e, portanto, estão suscetíveis a "todas as implicações sistêmicas e contextuais" (KRIEGER; FINATTO, 2004, p. 36) das línguas e das utilizações linguísticas. Uma dessas implicações linguísticas que são inerentes às terminologias é a variação, tanto formal quanto conceitual.

Com base em Cabré (2008), Costa e Fernández-Silva (2018, p. 97) afirmam que “a variação conceitual ocorre quando diferentes conceitualizações originam distintos conceitos para um mesmo referente", podendo ocasionar ou não variações formais. No que tange à variação formal, ela ocorre quando há variações na estrutura das unidades terminológicas e, no nosso caso, das UFEs. Ademais, as variações formais não necessariamente resultam em variações conceituais.

De acordo com Freixa (2002) e Fernández-Silva (2011), dentre os fatores que originam e/ou promovem variações terminológicas formais e conceituais no âmbito de uma mesma área técnico-científica, estão: (i) evolução do conhecimento, que geralmente resulta na reformulação de conceitos já pertencentes ao sistema conceitual da área; (ii) influências culturais ou de diferentes variantes linguísticas; (iii) variação ocasionada pelas formas distintas de segmentar a realidade entre diferentes escolas de pensamento, que, por vezes, designam de maneiras distintas um mesmo conceito (ou um conceito quase idêntico), ou vice-versa; (iv) pela flexibilidade dos próprios conceitos, que podem não possuir fronteiras precisas e evidentes; (v) perspectivas individuais do pesquisador/profissional, haja vista que "as referências, o conhecimento prévio, os interesses e os objetivos que guiam a conceitualização nunca serão exatamente 
iguais entre duas pessoas"'" (FERNÁNDEZ-SILVA, 2011, p. 69); (vi) motivações subjetivas dos profissionais/pesquisadores, como adequação linguística ao nível de especialidade do público-alvo, utilização de variações como recursos estilísticos para evitar repetições, dentre muitos outros fatores.

Além da variação, aspectos linguísticos como sinonímia, homonímia e polissemia também são naturais nas comunicações especializadas. Todavia, é relevante evidenciar que, considerando que a comunicação especializada requer níveis mínimos de objetividade e precisão, e tendo em vista os papéis cumpridos pelas terminologias na introdução, fixação e comunicação de conhecimentos especializados, a alta variação terminológica e a presença expressiva de sinônimos, homônimos e de polissemia no escopo de uma mesma área técnico-científica podem ser problemáticas.

O que percebemos ao analisar a terminologia designativa do PFOL é que, apesar de natural, a alta variação, em especial a variação conceitual sem consequências formais, pode influenciar negativamente a eficiência comunicativa de conhecimentos especializados entre públicos direta ou indiretamente envolvidos com a área. Isto porque, por vezes, uma mesma UFE possui concepções distintas e as concepções nem sempre são evidenciadas nas publicações, o que dificulta a apreensão do conceito exato sendo articulado pelos autores.

Esses e outros pontos de reflexão sobre a terminologia designativa do PFOL estão apresentados na Seção 5. Mas antes de passarmos à análise e discussão dos dados, na seção seguinte justificamos a eleição da Linguística de Corpus como metodologia neste estudo exploratório e descrevemos brevemente os procedimentos metodológicos realizados.

\footnotetext{
${ }^{6}$ No original: “[...] las referencias, el conocimiento previo, los intereses y los objetivos que guían la conceptualización nunca serán exactamente iguales entre dos personas" (tradução nossa).
} 


\section{Metodologia}

\subsection{Linguística de Corpus}

No âmbito das abordagens de bases linguísticas da Terminologia, as unidades terminológicas e UFEs são concebidas como tal, analisadas e definidas na materialização do discurso especializado, ou seja, nos textos em que ocorrem, que se constituem como seus habitat naturais (KRIEGER; FINATTO, 2004). É nesse contexto que a Linguística de Corpus (doravante LC) consiste em uma metodologia e/ou abordagem profícua para os estudos terminológicos e terminográficos.

A LC é uma metodologia/abordagem ${ }^{7}$ quanti-qualitativa de base empírica e estatística voltada à análise e descrição linguística por meio da investigação em corpora computadorizados (BERBER SARDINHA, 2004; PARODI, 2010; O'KEEFFE; McCARTHY, 2010). No escopo da LC, um corpus é um “conjunto de dados linguísticos textuais [em formato legível por computador] coletados criteriosamente com o propósito de servirem para a pesquisa de uma língua ou variedade linguística" (BERBER SARDINHA, 2004, p. 3).

Por meio da utilização de ferramentas computacionais, a LC permite a exploração de grandes quantidades de texto com rapidez impossível de ser alcançada manualmente. Ademais, as ferramentas possibilitam a organização dos dados de acordo com os propósitos da pesquisa, facilitando análises quali-quantitativas, bem como geram resultados cuja precisão promovem "maior confiabilidade e certeza nas análises quantitativas dos traços [e padrões] linguísticos em grandes amostras textuais" ${ }^{\prime \prime}$ (PARODI, 2010, p. 22). Em vista disso, a LC foi utilizada como metodologia para a compilação de dados e para as análises realizadas no estudo apresentado neste artigo.

\footnotetext{
${ }^{7}$ Os debates referentes ao estatuto da LC como metodologia, abordagem ou área dos estudos linguísticos são evidentes nas publicações sobre a LC. Para um panorama dessas concepções, ver Berber Sardinha (2000) e Shepherd (2009). Adiantamos que a LC foi utilizada neste estudo como metodologia, portanto, o estudo apresentado neste artigo é "baseado em corpus".

${ }^{8}$ No original: "[...] mayor confiabilidad y certeza en los análisis cuantitativos de los rasgos lingüísticos en grandes muestras de textos" (tradução nossa).
} 
Como mencionado na seção introdutória deste artigo, o corpus de estudo desta pesquisa é composto por 66 artigos publicados nos nove números da Revista SIPLE, totalizando 230.081 tokens ${ }^{9}$ e 18.731 types $^{10}$. Apesar de ser constituído por publicações de um único periódico da área e, portanto, não satisfazer os critérios de diversidade, balanceamento e representatividade (ALMEIDA; CORREIA, 2008), este corpus foi suficiente para a realização deste estudo, haja vista que não pretendemos realizar uma análise exaustiva, mas sim exploratória.

Na subseção seguinte, apresentamos brevemente os procedimentos metodológicos realizados neste estudo, desde a compilação do corpus até os procedimentos de análise empreendidos.

\subsection{Procedimentos metodológicos}

O primeiro procedimento metodológico foi a delimitação da fonte de compilação dos arquivos que comporiam o corpus de estudo. A Revista SIPLE foi selecionada devido aos seguintes fatores: (i) é um periódico inteiramente voltado à área de PFOL; (ii) por ter nove edições e um número considerável de artigos escritos por diversos autores, o procedimento de compilação do corpus seria realizado de maneira mais célere e o corpus teria tamanho suficiente para a realização deste estudo exploratório.

Delimitada a fonte de compilação, os próximos procedimentos metodológicos são subdivisíveis em duas grandes etapas: (i) compilação e preparação do corpus para processamento pelo WordSmith Tools 6.0 (SCOTT, 2012), doravante WST; (ii) processamento e análise do corpus de estudo. Estas duas etapas metodológicas estão descritas nas subseções seguintes.

\footnotetext{
${ }^{9}$ Ocorrências totais no corpus.

${ }^{10}$ Ocorrências totais no corpus, desconsiderando-se as que se repetem.
} 


\subsubsection{Compilação e preparação do corpus}

A primeira etapa metodológica contou com os seguintes procedimentos:

(i) Compilação dos artigos publicados nas nove edições da Revista SIPLE;

(ii) Atribuição de códigos aos arquivos para facilitar sua futura identificação;

(iii) Conversão dos arquivos compilados em .pdf ${ }^{11}$ para $\cdot$ docx $^{12}$, por meio do procedimento de $\mathrm{OCR}^{13}$ do programa $A B B Y Y$ FineReader ${ }^{14}$;

(iv) Revisão e limpeza de cada arquivo, excluindo informações pós-textuais;

(v) Conversão dos arquivos em .docx para .txt ${ }^{15}$.

Primeiramente acessamos a Revista SIPLE e fizemos o download de todos os números da revista, que estão disponibilizadas gratuitamente online em .pdf. Em seguida, cada artigo foi salvo em um arquivo separado e armazenado em um diretório específico. O resultado dessa etapa foi uma coletânea de 66 artigos em formato .pdf ${ }^{16}$.

Simultaneamente ao procedimento de download, um código foi atribuído a cada arquivo, para facilitar sua futura identificação. No código constam as seguintes informações: formato de publicação do arquivo, fonte de onde foi coletado, ano de publicação e nome e sobrenome do autor ${ }^{17}$. Nos casos em que duas publicações de um mesmo autor na mesma edição da revista foram identificadas, acrescentamos ao código números de acordo com a ordem do artigo na edição da revista.

\footnotetext{
11 Sigla de Portable Document Format, formato portátil de documento.

12 Extensão de arquivo desenvolvida pela Microsoft Corporation, legível pela ferramenta Microsoft Word do Microsoft Office Suite.

${ }^{13}$ Sigla de Optical Character Recognition, reconhecimento óptico de caracteres.

${ }^{14}$ Disponível em: https://www.abbyy.com/pt-br/finereader/ . Acesso em: 3 dez. 2020.

${ }_{15}$ Documento de texto sem formatação. Esse procedimento é necessário, pois arquivos em .txt são os mais satisfatoriamente processados pelo WST.

${ }^{16}$ É relevante evidenciar que os nove números da Revista SIPLE também contam com entrevistas e resenhas de livros, contudo apenas artigos foram selecionados para compor o corpus de estudo.

17 Nos casos de publicações em coautoria, inserimos apenas os sobrenomes dos autores para que o código não ficasse demasiadamente extenso.
} 
Feita a compilação e atribuição de códigos aos arquivos, o procedimento seguinte seria a conversão dos arquivos em formato .pdf para o formato .txt. Esse procedimento poderia ser facilmente realizado por meio da seleção das porções textuais nos arquivos em formato .pdf e posterior colagem no Bloco de Notas do Windows. Entretanto, os arquivos em .pdf disponibilizados pela revista são protegidos, o que não permitiu que o procedimento de cópia e colagem no Bloco de Notas fosse realizado. Portanto, recorremos ao programa $A B B Y Y$ FineReader, que permite a aplicação do reconhecimento óptico de caracteres e conversão de arquivos em .pdf para .docx. Por meio da utilização do programa em questão, cada arquivo, originalmente em .pdf, foi salvo em formato .docx e nomeado com o mesmo código atribuído ao arquivo original.

Após a conversão de todos os arquivos para formato .docx, a limpeza e correção dos arquivos foram realizadas. Como os elementos pós-textuais, quadros, figuras e informações de autoria não seriam pertinentes para a análise que objetivávamos realizar, essas informações foram excluídas dos arquivos .docx. Ademais, foi necessário revisar criteriosamente os arquivos tendo em vista corrigir eventuais erros ocasionados pelo procedimento de OCR do ABBYY FineReader. Ao término dos procedimentos de limpeza e correção de cada arquivo, cada texto foi copiado e colado no Bloco de Notas do Windows e salvo em formato .txt.

A Figura 1, a seguir, apresenta resumidamente o resultado dos procedimentos descritos nesta subseção. 
Figura 6 - Recorte dos diretórios do corpus e exemplo da codificação atribuída aos arquivos.

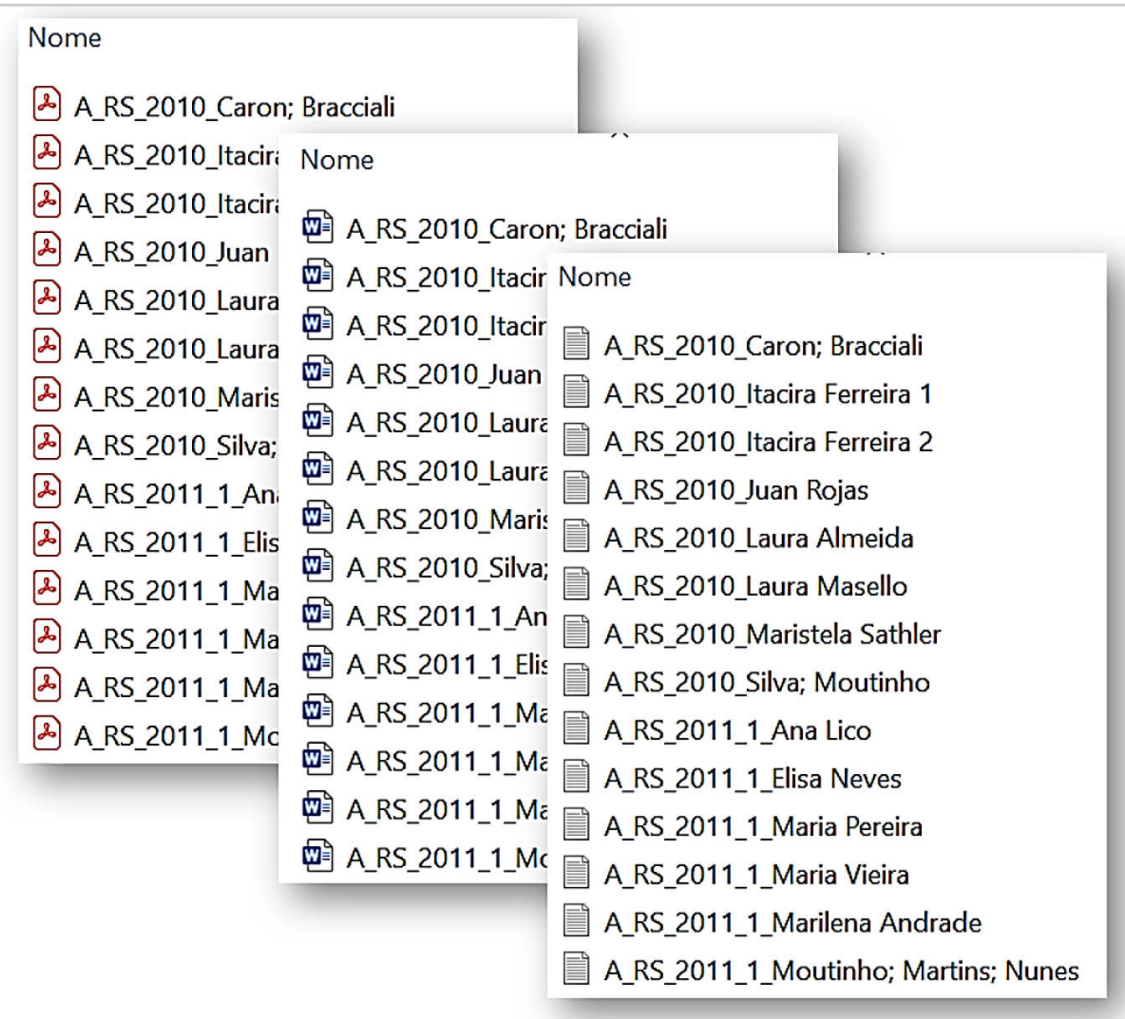

Fonte: elaborada pelo autor.

\subsubsection{Processamento e análise do corpus}

Nessa etapa metodológica, o primeiro procedimento foi a utilização do Text Converter do WST para a conversão em massa da codificação dos arquivos em .txt (que via de regra é UTF-8) para a codificação utilizada pelo WST (Unicode).

Feito isso, o corpus foi carregado no WST e, por meio da ferramenta Concord do WST, buscamos por "português" e "portuguesa", a fim de encontrar candidatos a UFEs possivelmente utilizados para designar a área e potenciais subáreas do PFOL. Esse procedimento resultou na geração do total de 1.680 linhas de concordância. Em seguida, organizamos as linhas de concordância por ordem alfabética seguindo a codificação atribuída aos arquivos nas etapas anteriormente descritas neste artigo, como ilustrado na Figura 2, a seguir. 
Figura 7 - Recorte das linhas de concordância organizadas alfabeticamente segundo os códigos atribuídos aos arquivos.

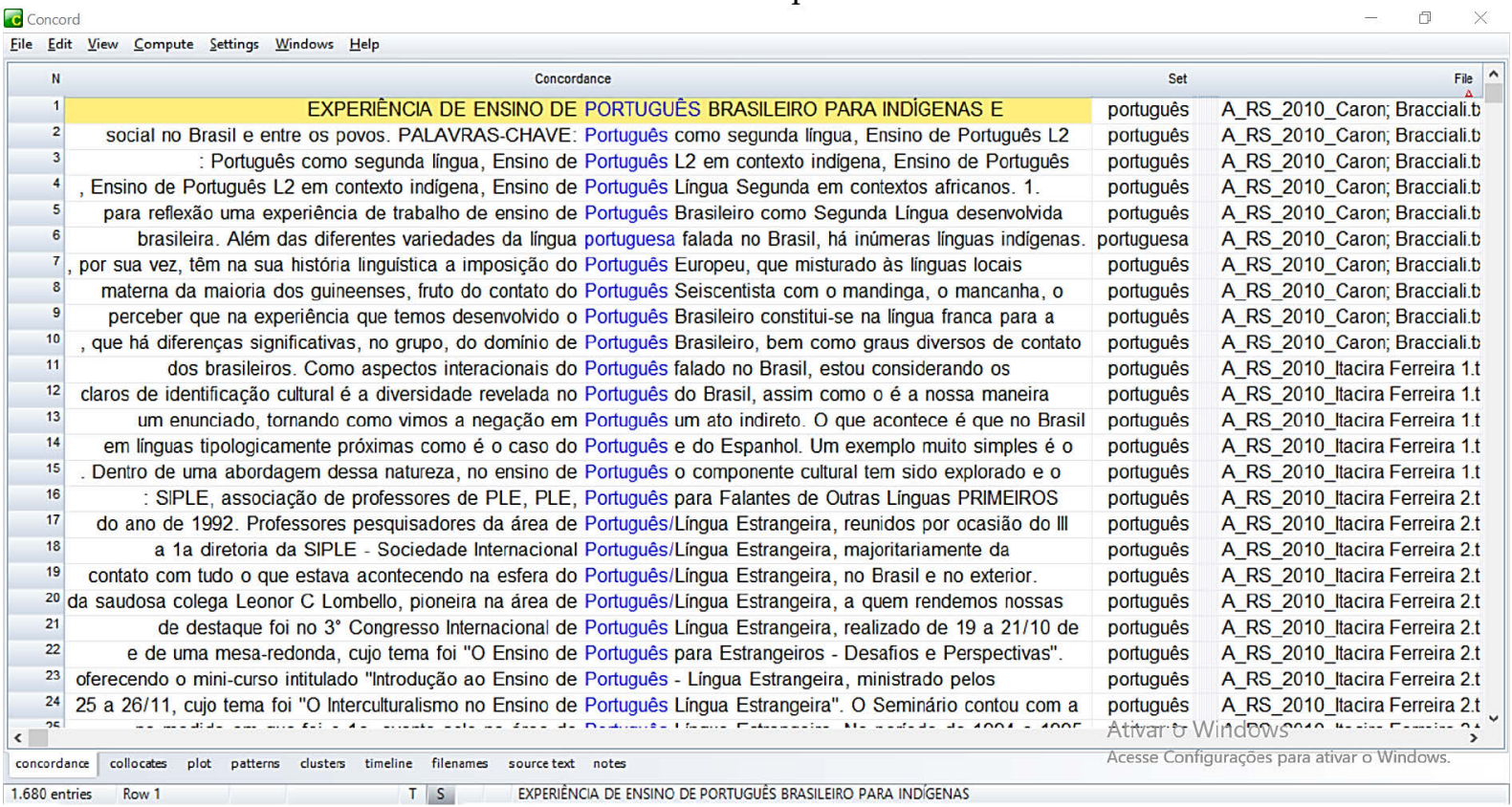

Fonte: extraída de análise no WST.

Após os procedimentos descritos, iniciamos a análise das 1.680 linhas de concordância geradas. Cada candidato a UFE identificado foi inserido em uma tabela em que constavam o código dos arquivos em que cada candidato a UFE ocorreu, bem como o número de ocorrências em cada um desses arquivos. Apresentamos na Figura 3 um recorte da referida tabela de informações sobre as ocorrências dos candidatos a UFEs.

Figura 8 - Recorte da tabela de informações sobre a ocorrências dos candidatos a UFEs.

\begin{tabular}{|c|c|c|}
\hline Candidato a UFE & $\mathbf{N}^{0}$ & Arquivo \\
\hline Português brasileiro para indígenas e africanos & 1 & A RS 2010 Caron; Bracciali \\
\hline Português como segunda língua & 1 & A RS 2010_Caron; Bracciali \\
\hline Português L2 em contexto indígena & 1 & A RS 2010 Caron; Bracciali \\
\hline Português Língua Segunda em contextos africanos & 1 & A RS 2010 Caron; Bracciali \\
\hline Português Brasileiro como Segunda Língua & 1 & A RS 2010 Caron; Bracciali \\
\hline Português para Falantes de Outras Línguas & 1 & A RS 2010 Itacira Ferreira 2 \\
\hline Português/Língua Estrangeira & 4 & A_RS_2010_Itacira Ferreira 2 \\
\hline Português Língua Estrangeira & 3 & A_RS_2010_Itacira Ferreira 2 \\
\hline Português para Estrangeiros & 2 & A RS 2010 Itacira Ferreira 2 \\
\hline Português - Língua Estrangeira & 1 & A RS 2010 Itacira Ferreira 2 \\
\hline Português como Língua Estrangeira & 4 & A RS 2010 Itacira Ferreira 2 \\
\hline Português como segunda língua para surdos e indígenas & 1 & A RS 2010 Itacira Ferreira 2 \\
\hline Português como Nova Língua & 1 & A_RS_2010_Itacira Ferreira 2 \\
\hline Português Língua Estrangeira & 1 & A_RS 2010_Juan Rojas \\
\hline português como segunda língua & 1 & A RS 2010 Juan Rojas \\
\hline Português para Falantes de Outras Línguas & 1 & A RS 2010 Juan Rojas \\
\hline Português para Estrangeiros & 1 & A RS 2010 Juan Rojas \\
\hline português como língua internacional & 1 & A_RS_2010_Juan Rojas \\
\hline
\end{tabular}

Fonte: elaborada pelo autor. 
Foi necessário fazer esse levantamento do número de ocorrências e do número de arquivos em que cada candidato a UFE ocorreu, pois, em virtude da alta variação terminológica presente no corpus, o critério de ocorrência mínima em três arquivos distintos foi eleito para determinar se um agrupamento lexical seria considerado uma UFE designativa e, consequentemente, seria selecionado para análise neste estudo. Isto porque grande parte dos candidatos a UFEs identificados possuem as mesmas características de estruturas frasais não terminológicas, portanto, o critério de ocorrência em arquivos distintos auxiliou na delimitação da extensão das UFEs, bem como na redução da variação terminológica oriunda de escolhas estilísticas dos autores no momento da análise ${ }^{18}$.

Antes de passarmos aos resultados, é relevante pontuar que os candidatos e UFEs extraídos não necessariamente foram utilizados pelos autores para denominar especificamente subáreas de atuação, mas também foram utilizados como citações de nomes de cursos, de livros, de departamentos etc. Contudo, como possuem potencial papel designativo da área e de subáreas de atuação do PFOL, foram selecionados como candidatos e UFEs designativas neste estudo. Por fim, evidenciamos que a variação entre letras maiúsculas e minúsculas foi ignorada, por não ser aspecto relevante para esta pesquisa.

\section{Resultados e discussão}

Das 1.680 linhas de concordância geradas para os nódulos de busca "português" e "portuguesa", 479 continham candidatos a UFEs que possivelmente podem ser utilizados como designadores da área do PFOL e/ou de potenciais subáreas de atuação. Devido às limitações de espaço deste artigo, não será possível apresentar a tabela com

\footnotetext{
${ }^{18}$ É relevante evidenciar que um número considerável de candidatos a UFEs são recorrentes no corpus, porém em publicações de um mesmo autor. Em vista disso, a delimitação de ocorrência mínima do mesmo agrupamento lexical em três arquivos distintos auxiliou a reduzir o número destes casos no momento da análise.
} 
todos os candidatos a UFEs identificados no corpus. Não obstante, no Quadro 1, a seguir, apresentamos as UFEs obtidas após a filtragem pelo critério de ocorrência mínima em três arquivos.

Quadro 5 - UFEs (co)ocorrentes em no mínimo três arquivos do corpus de estudo.

\begin{tabular}{|c|c|c|c|}
\hline \multicolumn{4}{|c|}{ PORTUGUÊS (COMO) LÍNGUA ESTRANGEIRA } \\
\hline No & UFEs & OCORRÊNCIAS & ARQUIVOS \\
\hline 1 & Português como Língua Estrangeira & 60 & 31 \\
\hline 2 & Português Língua Estrangeira & 61 & 24 \\
\hline \multicolumn{4}{|c|}{ PORTUGUÊS/LÍNGUA PORTUGUESA PARA ESTRANGEIROS } \\
\hline No & UFEs & OCORRÊNCIAS & ARQUIVOS \\
\hline 3 & Português para Estrangeiros & 41 & 16 \\
\hline 4 & Língua Portuguesa para Estrangeiros & 7 & 5 \\
\hline \multicolumn{4}{|c|}{ PORTUGUÊS COMO SEGUNDA LÍNGUA } \\
\hline No & UFE & OCORRÊNCIAS & ARQUIVOS \\
\hline 5 & Português como Segunda Língua & 26 & 14 \\
\hline \multicolumn{4}{|c|}{ PORTUGUÊS (COMO) LÍNGUA DE ACOLHIMENTO } \\
\hline No & UFEs & OCORRÊNCIAS & ARQUIVOS \\
\hline 6 & Português como Língua de Acolhimento & 35 & 8 \\
\hline 7 & Português Língua de Acolhimento & 11 & 3 \\
\hline \multicolumn{4}{|c|}{ PORTUGUÊS COMO LÍNGUA DE HERANÇA } \\
\hline No & UFE & OCORRÊNCIAS & ARQUIVOS \\
\hline 8 & Português como Língua de Herança & 16 & 7 \\
\hline \multicolumn{4}{|c|}{ PORTUGUÊS PARA FALANTES DE OUTRAS LÍNGUAS } \\
\hline No & UFE & OCORRÊNCIAS & ARQUIVOS \\
\hline 9 & Português para Falantes de Outras Línguas & 9 & 6 \\
\hline \multicolumn{4}{|c|}{ PORTUGUÊS COMO LÍNGUA ADICIONAL } \\
\hline No & UFE & OCORRÊNCIAS & ARQUIVOS \\
\hline 10 & Português como Língua Adicional & 6 & 5 \\
\hline
\end{tabular}

Fonte: elaborado pelo autor.

Como apresentado no Quadro 1, identificamos em nosso corpus de estudo 10 UFEs designativas recorrentes em, no mínimo, três arquivos do corpus. Essas UFEs podem ser agrupadas em sete categorias, haja vista que algumas delas são variações. 
No que tange à variação formal das UFEs apresentadas no Quadro 1, "Português como Segunda Língua", "Português como Língua de Herança", "Português para Falantes de Outras Línguas" e "Português como Língua Adicional" são as que menos variam no corpus, ou seja, são as que possuem um nível de padronização terminológica formal mais alto. As demais UFEs variam formalmente de duas maneiras:

(i) utilização ou supressão da preposição "como": Português (como) Língua Estrangeira; Português (como) Língua de Acolhimento;

(ii) alternância entre "português" e "língua portuguesa": (Português/Língua Portuguesa) para Estrangeiros.

Com exceção de "Português como Língua Estrangeira" e "Português Língua Estrangeira", que são UFEs variantes concorrentes em uma parcela quantitativamente próxima de arquivos, as demais UFEs variantes possuem um número discrepante de ocorrências totais e de ocorrências em diferentes arquivos. Se fosse necessário eleger uma única UFE como referência padrão para cada grupo de variantes, seria possível considerar o aspecto quantitativo de utilizações dessas UFEs no corpus, e como resultado teríamos: (i) Português como Língua Estrangeira; (ii) Português para Estrangeiros; (iii) Português como Segunda Língua; (iv) Português como Língua de Acolhimento; (v) Português como Língua de Herança; (vi) Português para Falantes de Outras Línguas e (vii) Português como Língua Adicional.

Apenas pelas indicações quantitativas e pela análise da variação formal, seria possível afirmar que a área que designamos como PFOL neste estudo possui seis subáreas de atuação. Contudo, por meio da análise qualitativa do corpus, identificamos que, por vezes, "Português (como) Língua Estrangeira", "Português para Falantes de Outras Línguas" e "Português como Língua Adicional" são utilizados como sinônimos 
por alguns pesquisadores. Nestes casos, estas três UFEs são utilizadas como designadoras da área geral ${ }^{19}$.

Quando estas UFEs são diferenciadas a nível conceitual, com exceção de PFOL, em que observamos a mesma concepção em todos os trabalhos em que esta UFE ocorre, é possível perceber as seguintes concepções:

(i) Português (como) Língua Estrangeira: ensino-aprendizagem da língua portuguesa em contextos de não imersão linguística;

(ii) Português como Língua Adicional: ensino-aprendizagem da língua portuguesa para públicos-alvo trilíngues ou poliglotas ${ }^{20}$;

Isto significa que as UFEs em questão variam conceitualmente, mas mantêm, quase sempre, a mesma estrutura formal. Esses casos podem ser problemáticos, pois, muitas vezes, as concepções distintas não estão evidenciadas nos textos, o que pode ocasionar problemas na comunicação especializada, tanto entre profissionais/pesquisadores já atuantes, como entre estes profissionais/pesquisadores e os que estão em formação. Ademais, essa problemática conceitual pode se estender aos usuários indiretos das terminologias, como tradutores e gestores da informação.

Sob o prisma de nossas análises, acreditamos que seria relativamente problemático designar a área como um todo por meio da UFE "Português (como) Língua Estrangeira", haja vista que há concepções distintas em relação a esta UFE, principalmente no que tange à especificidade de ensino-aprendizagem em contextos de não imersão linguística (que pode ser caracterizada como uma subárea de atuação). Como

\footnotetext{
${ }^{19}$ Também identificamos no corpus a UFE Português como Língua Não Materna (com variações) como designadora da área geral, mas como as ocorrências não alcançaram o critério de ocorrência mínima estabelecido para a análise, esta UFE não foi apresentada no Quadro 1.

${ }^{20}$ Nesses casos, o conceito de língua adicional refere-se a todas as línguas adquiridas após a língua materna e a segunda língua. Ademais, não identificamos especificações relacionadas ao ensino-aprendizagem em contextos de imersão ou não imersão linguística.
} 
a área como um todo não atua apenas neste tipo de contexto, a utilização desta UFE para designar a área promoveria imprecisões terminológicas.

Do mesmo modo, a utilização de "Português como Língua Adicional" como designação da área também parece problemática, haja vista que há variação conceitual em relação à esta UFE, em especial no que concerne ao ensino-aprendizagem de português para públicos-alvo trilíngues e/ou poliglotas (que também pode ser caracterizado como uma potencial subárea de atuação).

Isto posto, dentre as UFEs identificadas como designativas da área como um todo, a UFE “Português para Falantes de Outras Línguas” parece, a priori, a mais adequada, pois possui natureza mais geral (deste modo, funcionando adequadamente como hiperônimo para as demais subáreas de atuação) e, dentre as UFEs sob discussão, ela é a mais formalmente e conceitualmente estável, apesar de não ser a mais frequentemente utilizada pelos pesquisadores como designação da área. Pelos motivos apresentados, utilizamos neste artigo "Português para Falantes de Outras Línguas" como UFE designativa da área como um todo.

No caso das UFEs "Português para Estrangeiros" e "Língua Portuguesa para Estrangeiros", percebemos que, em geral, elas são utilizadas como sinônimas de "Português para Falantes de Outras Línguas", "Português (como) Língua Estrangeira" e "Português como Língua Adicional" (quando estas duas últimas UFEs são utilizadas como referência à área como um todo). Não percebemos uma concepção mais específica que possibilite diferenciar conceitualmente “Português/Língua Portuguesa para Estrangeiros" das outras UFEs analisadas. Portanto, nosso corpus indica que a UFE em questão não se constitui como designativa de uma subárea do PFOL, ou seja, ela é apenas utilizada como UFE alternativa para as outras que estão em relação de sinonímia.

Em vista do que foi exposto, se considerarmos "Português como Língua Adicional" como uma subárea voltada ao ensino-aprendizagem da língua portuguesa 
para/por falantes não lusófonos trilíngues e/ou poliglotas e "Português como Língua Estrangeira" como subárea voltada ao ensino-aprendizagem da língua portuguesa para alunos não lusófonos em contextos de não imersão linguística, seria possível esboçar a árvore de domínio do PFOL da seguinte maneira:

Figura 9 - Esboço da árvore de domínio do PFOL.

\section{Português para Falantes de Outras Línguas

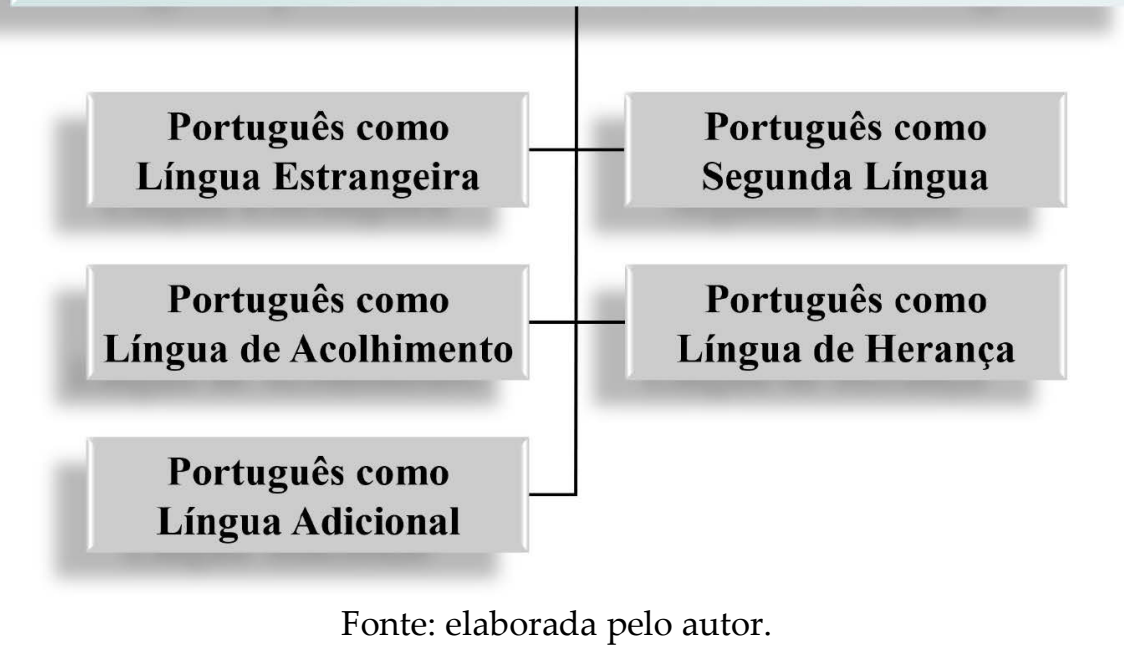

Pontuamos que, devido à natureza exploratória da pesquisa, a árvore de domínio do PFOL apresentada na Figura 4 é apenas um esboço dos resultados de nossas análises neste corpus de estudo. Se replicarmos a análise em um corpus maior e mais representativo, pode ser que cheguemos a resultados diferentes dos que foram apresentados.

Por meio de nossas análises, observamos que a alta diversidade de UFEs designativas de área e subáreas do PFOL e a alta variação terminológica (principalmente a nível formal) entre estas UFEs designativas são características da terminologia sob análise. No Quadro 2, a seguir, apresentamos um dos agrupamentos de candidatos a UFEs realizados no momento da análise, de modo a ilustrar a diversidade e variação terminológica formal observadas no corpus de estudo. 
Quadro 6 - Exemplo da diversidade e variação terminológica formal de Português (como) Língua Estrangeira.

\begin{tabular}{|c|l|c|c|}
\hline \multicolumn{3}{|c|}{ PORTUGUÊS (COMO) LÍNGUA ESTRANGEIRA } \\
\hline $\mathbf{N} N$ & \multicolumn{1}{|c|}{ CANDIDATOS A UFE } & 58 & 30 \\
\hline 1 & Português como Língua Estrangeira & 56 & 25 \\
\hline 2 & Português Língua Estrangeira & 3 & 2 \\
\hline 3 & Língua Portuguesa como Língua Estrangeira & 3 & 2 \\
\hline 4 & Português (PLE) & 2 & 2 \\
\hline 5 & Língua Portuguesa (PLE) & 4 & 1 \\
\hline 6 & Português/Língua Estrangeira & 2 & 1 \\
\hline 7 & Português como LE & 2 & 1 \\
\hline 8 & Português como Língua Estrangeira/Adicional & 1 & 1 \\
\hline 9 & Português - Língua Estrangeira & 1 & 1 \\
\hline 10 & Língua Portuguesa Língua Estrangeira & 1 & 1 \\
\hline 11 & $\begin{array}{l}\text { Português como Língua Estrangeira para Imigrantes e Refugia- } \\
\text { dos }\end{array}$ & 1 & 1 \\
\hline 12 & Português na Perspectiva de uma Língua Estrangeira & 1 & 1 \\
\hline 13 & Língua Portuguesa Ensinada como Língua Estrangeira & 1 & 1 \\
\hline 14 & Língua Portuguesa Falada no Brasil como Língua Estrangeira & 1 & 1 \\
\hline 15 & Português Europeu como Língua Estrangeira & 1 & 1 \\
\hline 16 & Língua Português L2/LE & 1 & 1 \\
\hline 17 & Português LE & 1 & 1 \\
\hline 18 & Português LE/SL & 1 & 1 \\
\hline 19 & Português como PLE & 1 & 1 \\
\hline 20 & Português PLE & 1 & 1 \\
\hline 21 & Português (LE) & & \\
\hline
\end{tabular}

Fonte: elaborado pelo autor.

O Quadro 2 é um recorte do quadro original elaborado ao longo da análise deste estudo. No quadro original, havia 30 formas variantes para designação de Português (como) Língua Estrangeira ${ }^{21}$. No Quadro 2, apresentamos 19 dessas formas, de modo a ilustrar essa variação terminológica.

A alta diversidade de UFEs designativas e a expressiva variação terminológica a nível formal foram observadas, em maior ou menor grau, em todos os agrupamentos realizados durante as análises, o que indica que a terminologia designativa do PFOL é

${ }^{21}$ É relevante pontuar que, em alguns casos, o número total de variações é maior do que o número de ocorrências da UFE mais estável. 
naturalmente diversa e variante. Não analisamos se essas variações formais têm consequências conceituais/cognitivas, mas este pode ser um potencial tópico de estudo para pesquisas futuras.

No Quadro 2, é possível observar que dos candidatos a UFEs apresentados, 16 deles ocorreram em apenas um trabalho. A partir disso, poderíamos inferir que cada autor possui uma forma característica de designação de Português (como) Língua Estrangeira. Não obstante, o que observamos foi que a variação terminológica não se torna explícita apenas no contraste entre trabalhos distintos, mas ela também ocorre no escopo de um mesmo trabalho.

Acreditamos que as possíveis motivações dessa "autovariação" (FREIXA, 2005), podem ser: (i) utilização de variações como recursos linguísticos para evitar repetições e promover melhor fluência na leitura do texto, (ii) concepções individuais de determinados autores ou (iii) influências diatópicas, diastráticas, diafásicas ou influências de filiações a diferentes escolas teóricas ${ }^{22}$. As motivações dessas variações na terminologia designativa do PFOL também se constituem como um tópico de estudo profícuo para futuras pesquisas terminológicas.

Apresentamos no Quadro 3, a seguir, algumas das variações terminológicas encontradas em quatro artigos de diferentes autores. Em cada um dos arquivos indicados no quadro em questão, as variações terminológicas agrupadas constituíam-se como designação para um mesmo referente em cada artigo, ou seja, são variações formais, $a$ priori, sem consequências conceituais.

\footnotetext{
${ }^{22}$ As possíveis motivações de variação terminológica mencionadas neste parágrafo foram extraídas de panoramas apresentados em Freixa (2002) e Fernández-Silva (2011).
} 
Quadro 7 - Exemplos de variação terminológica no escopo de um mesmo trabalho²3.

\begin{tabular}{|l|l|}
\hline \multicolumn{1}{|c|}{ CANDIDATOS A UFE } & \multicolumn{1}{c|}{ ARQUIVO } \\
\hline Português para Falantes de Outras Línguas & A_RS_2010_Itacira Ferreira 2 \\
\hline Português/Língua Estrangeira & A_RS_2010_Itacira Ferreira 2 \\
\hline Português Língua Estrangeira. & A_RS_2010_Itacira Ferreira 2 \\
\hline Português como Língua Estrangeira & A_RS_2010_Itacira Ferreira 2 \\
\hline \multicolumn{2}{|c|}{} \\
\hline Português como segunda língua & A_RS_2010_Caron; Bracciali \\
\hline Português L2 & A_RS_2010_Caron; Bracciali \\
\hline Português Língua Segunda & A_RS_2010_Caron; Bracciali \\
\hline Português Brasileiro como Segunda Língua & A_RS_2010_Caron; Bracciali \\
\hline \multicolumn{2}{|c|}{} \\
\hline Português como língua de herança & A_RS_2011_1_Ana Lico \\
\hline Português Língua de Herança & A_RS_2011_1_Ana Lico \\
\hline Língua Portuguesa como língua de herança & A_RS_2011_1_Ana Lico \\
\hline \multicolumn{2}{|c|}{} \\
\hline Português como Língua de Herança & A_RS_2011_1_Vivaldo Santos \\
\hline português como PLE & A_RS_2011_1_Vivaldo Santos \\
\hline Português como segunda língua & A_RS_2011_1_Vivaldo Santos \\
\hline Português Língua Segunda & A_RS_2011_1_Vivaldo Santos \\
\hline Português para Falantes de Língua de Herança & A_RS_2011_1_Vivaldo Santos \\
\hline
\end{tabular}

Fonte: elaborado pelo autor.

Apesar de a variação terminológica ser uma característica intrínseca às terminologias, por serem compostas por unidades primeiramente linguísticas que funcionam como unidades terminológicas em contextos pragmaticamente marcados (CABRÉ, 1999), ela pode ser problemática, principalmente no que tange às variações conceituais, e mais ainda em relação às variações conceituais sem consequências formais, como mencionamos anteriormente nesta seção. Isto porque a terminologia de uma área técnico-científica cumpre um papel fundamental na sistematização dos conhecimentos produzidos nas áreas de especialidade e na comunicação desses conhecimentos entre indivíduos diretamente ou indiretamente ligados a essas áreas. Desta forma, é relevante que as terminologias das áreas técnico-científicas sejam minimamente es-

\footnotetext{
${ }^{23} \mathrm{Na}$ elaboração deste quadro, analisamos os arquivos manualmente, com o intuito de desconsiderar citações de nomes de livros, de cursos, de modo a evidenciar, de maneira mais precisa, a autovariação terminológica. Esta análise foi realizada por meio da ferramenta Concord do WST.
} 
táveis e precisas (formalmente e conceitualmente), pois a própria comunicação especializada requer um nível minimamente alto de precisão conceitual e de objetividade (cf. Seção 3).

Os dados obtidos e discutidos neste estudo exploratório indicam uma potencial necessidade de realização de uma padronização (formal e conceitual) da terminologia designativa da área e subáreas do PFOL, haja vista que identificamos uma expressiva variação terminológica formal e conceitual, bem como a presença de sinonímias (totais ou parciais) e polissemias na terminologia em questão.

Apesar de este estudo exploratório ter sido realizado com base em um corpus consideravelmente pequeno e não representativo da área como um todo, as reflexões apresentadas são relevantes para dar início a estudos mais abrangentes e aprofundados em relação à terminologia designativa da área e de subáreas do PFOL. Outrossim, as análises apresentadas indicam potenciais tópicos de estudo para futuras pesquisas e projetos no âmbito do PFOL, como a sistematização da árvore de domínio e do campo conceitual da área, a descrição da variação formal e conceitual, as motivações da variação terminológica (formal e conceitual), as consequências formais das variações conceituais e/ou consequências conceituais das variações formais, bem como as relações de sinonímia entre UFEs designativas da área e subáreas do PFOL.

\section{Considerações finais}

Neste artigo, apresentamos um estudo exploratório cujo o objetivo foi analisar a terminologia designativa da área e de subáreas do PFOL. A partir dos dados oriundos deste estudo exploratório, traçamos reflexões iniciais sobre a terminologia designativa desta área, focalizando nossas reflexões nas designações de possíveis subáreas do PFOL, na diversidade de UFEs que compõem a terminologia em questão, bem como na variação (formal e conceitual) observada no corpus de estudo. 
Por meio deste estudo, identificamos cinco potenciais subáreas do PFOL, a saber: (i) Português como Língua Estrangeira, (ii) Português como Segunda Língua, (iii) Português como Língua de Acolhimento, (iv) Português como Língua de Herança e (v) Português como Língua Adicional.

Outrossim, nas análises apresentadas, observamos que, por vezes, algumas UFEs designativas estão em relação de sinonímia total ou parcial (como é o caso de "Português/Língua Portuguesa para Estrangeiros", "Português para Falantes de Outras Línguas", "Português como Língua Estrangeira" e “Português como Língua Adicional" quando utilizadas como designação da área como um todo), assim como identificamos UFEs que variam conceitualmente, como "Português como Língua Estrangeira" e "Português como Língua Adicional", ambas funcionando como denominações da área como um todo ou como designações de potenciais subáreas específicas.

Apesar de termos identificado UFEs relativamente mais estáveis a nível formal (como "Português para Falantes de Outras Línguas", "Português como Segunda Língua", "Português como Língua de Herança" e "Português como Língua Adicional”), também identificamos uma alta variação terminológica formal, tanto na comparação entre diferentes trabalhos como no escopo de um mesmo artigo.

Os dados analisados indicam que a variação (formal e conceitual) é característica da terminologia designativa da área do PFOL. Contudo, essa variação pode se tornar problemática no que tange às comunicações especializadas, principalmente nos casos de variação conceitual sem consequências formais, haja vista que as diferentes concepções nem sempre são evidenciadas nos textos analisados.

A título de exemplificação, em muitos casos não é possível identificar se, por meio da utilização da UFE "Português como Língua Estrangeira”, o autor refere-se à área como um todo, à uma subárea focalizada no ensino/aprendizagem de português em contextos de não imersão linguística ou se o autor possui outra concepção diferente 
das identificadas neste estudo. Portanto, nossas análises indicam uma possível necessidade de padronização sistemática, tanto formal como conceitual, da terminologia designativa do PFOL, de modo a otimizar a comunicação especializada no âmbito desta área.

É relevante pontuar que, por serem oriundos de um estudo exploratório em um corpus relativamente pequeno e não representativo da área, os resultados deste estudo não podem ser generalizados e são contestáveis. Por outro lado, as reflexões apresentadas sinalizam potenciais tópicos de estudo para pesquisas voltadas à terminologia designativa do PFOL, como a sistematização da árvore de domínio e do campo conceitual da área, a descrição da variação formal e conceitual, a investigação sobre as motivações da variação terminológica da área, sobre as consequências da variação formal no nível cognitivo e consequências formais ocasionadas pelas variações conceituais, bem como a descrição das relações de sinonímia entre as UFEs designativas de área e subáreas do PFOL.

\section{Referências Bibliográficas}

ALMEIDA, G. M. B. Teoria Comunicativa da Terminologia (TCT): uma aplicação. 2000. 290 f. Tese (Doutorado em Lingüística e Língua Portuguesa) - Faculdade de Ciências e Letras, Universidade Estadual Paulista, Araraquara, 2000.

ALMEIDA, G. M. B.; CORREIA, M. Terminologia e corpus: relações, métodos e recursos. In: TAGNIN, S. E. O.; VALE, O. A. (org.). Avanços da Linguística de Corpus no Brasil. São Paulo: Humanitas, 2008. p. 67-94.

AMADO, R. S. O ensino de português como língua de acolhimento para refugiados. Revista SIPLE, Brasília, v. 4, n. 2, p. 11-18, 2013. Disponível em: https://docs.wixstatic.com/ugd/aa72b0 9aeb1cd15ab547df801c509e7978e193.pdf. Acesso em: 13 dez. 2020.

AMADO, R. S. Português como segunda língua para comunidades de trabalhadores transplantados. Revista SIPLE, Brasília, v. 2, n. 1, p. 86-97, 2011. Disponível em: https://docs.wixstatic.com/ugd/aa72b0 7616227cd98b4caaa9fc268dbd2274b6.pdf.

Acesso em: 13 dez. 2020. 
BATISTA, M. R. Desestrangeirização em português como língua segunda: o caso de estudantes alemães e italianos. Revista SIPLE, Brasília, v. 2, n. 2, p. 42-60, 2011. Disponível em:

https://docs.wixstatic.com/ugd/aa72b0 a26c03eab0e34f5b90ba220b9e1700dd.pdf. Acesso em: 13 dez. 2020.

BECKHAUSER, A. S. A língua portuguesa como recurso da política externa brasileira à luz da diplomacia cultural. Domínios de Lingu@gem, Uberlândia, v. 12, n. 2, p. 784802, 2018. DOI https://doi.org/10.14393/DL34-v12n2a2018-2.

BERBER SARDINHA, T. Lingüística de Corpus. Barueri: Manole, 2004.

BERBER SARDINHA, T. Lingüística de Corpus: histórico e problemática. D.E.L.T.A., São Paulo, v. 16, n. 2, p. 323-367, 2000. DOI https://doi.org/10.1590/S010244502000000200005.

CABRÉ, M. T. Terminology: theory, methods and applications. Edição de Juan Carlos Sager. Amsterdam: John Benjamins Publishing Company, 1999. DOI https://doi.org/10.1075/tlrp.1.

COSTA, L. A.; FERNÁNDEZ-SILVA, S. A variação denominativa explícita na Lexicografia no Brasil: pressupostos para a organização microestrutural do Dicionário de Lexicografia Brasileira. Ibérica, Castelló, n. 36, p. 95-118, 2018. Disponível em: https://dialnet.unirioja.es/servlet/articulo?codigo=6641091. Acesso em: 17 dez. 2020.

FERNÁNDEZ-SILVA, S. Variación terminológica y cognición: factores cognitivos en la denominación del concepto especializado. 2010. 380 f. Tesis (Doctorado en Ciencias del Lenguaje y Lingüística Aplicada) - Departament de Traducció i Ciències del Llenguatge, Universitat Pompeu Fabra, Barcelona, 2011. Disponível em: http://hdl.handle.net/10803/22638. Acesso em: 13 set. 2020.

FREIXA, J. La variació terminològica: anàlisi de la variació denominativa en textos de diferent grau d'especialització de l'àrea de medi ambient. 2002. 397 f. Tesi (Doctorado en Filologia Catalana) - Departament de Filologia Catalana, Universitat de Barcelona, Barcelona, 2002. Disponível em: http://hdl.handle.net/10803/1677. Acesso em: 13 set. 2020.

FREIXA, J. Variación terminológica: ¿Por qué y para qué? Meta, Montreal, v. 50, n. 4, [s.p.], 2005. Disponível em: https://www.erudit.org/en/journals/meta/2005-v50-n4meta1024/019917ar/. Acesso em: 13 set. 2020. 
JATOBÁ, J. R. Políticas linguística e externa chinesa: um breve panorama do ensino de LEs e do PLE na China. Revista SIPLE, Brasília, v. 5, n. 1, p. 55-72, 2015. Disponível em: $\quad$ https://75594e48-8adc-4b90-bea7-68134515f6e2.filesusr.com/ugd/aa72b0 02a55192d0fd48fb84677c235e0b3a37.pdf. Acesso em: 13 set. 2020.

KRIEGER, M. G.; FINATTO, M. J. B. Introdução à terminologia: teoria e prática. São Paulo: Contexto, 2004.

MALAGUTI, S. Bilinguismo e o aprendizado do português no exterior: vantagens, desvantagens e mitos. Revista SIPLE, Brasília, v. 5, n. 1, p. 40-47, 2015. Disponível em: https://75594e48-8adc-4b90-bea7-68134515f6e2.filesusr.com/ugd/aa72b0 02a55192d0fd48fb84677c235e0b3a37.pdf. Acesso em: 13 set. 2020.

MOITA LOPES, L. P. (org.). O português no século XXI: cenário geopolítico e sociolinguístico. São Paulo: Parábola Editorial, 2013.

O'KEEFFE, A.; McCARTHY, M. (ed.). The Routledge Handbook of Corpus Linguistics. Abingdon: Routledge, 2010. DOI https://doi.org/10.4324/9780203856949.

PARODI, G. Lingüística de Corpus: de la teoría a la empiria. Madrid: Iberoamericana, 2010. DOI https://doi.org/10.31819/9783865278715

RETO, L. A. et al. Novo atlas da língua portuguesa. Lisboa: INCM, 2016.

REY, A. Essays on Terminology. Tradução e edição de Juan Carlos Sager. Amsterdam: John Benjamins Publishing Company, 1995. DOI https://doi.org/10.1075/btl.9.

SCOTT, M. WordSmith Tools version 6. Stroud: Lexical Analysis Software, 2012. Disponível em: https://www.lexically.net/wordsmith/downloads/. Acesso em: 13 set. 2020.

SHEPHERD, T. M. G. O estatuto da Linguística de Corpus: metodologia ou área da Linguística? Matraga, Rio de Janeiro, v. 16, n. 24, p. 150-172, 2009. Disponível em: https://www.e-publicacoes.uerj.br/index.php/matraga/article/view/27801/19922.

Acesso em: 17 set. 2020. 